\title{
Biologically Inspired Computing System for Facial Emotion Detection: a Design Approach
}

\author{
Sonali Navghare \\ Research Scholar \\ G. H. Raisoni College of \\ Engineering, Nagpur
}

\author{
Shubhangi Giripunje \\ Assistant Professor \\ G. H. Raisoni College of \\ Engineering, Nagpur
}

\author{
Preeti Bajaj \\ Professor \\ G. H. Raisoni College of \\ Engineering, Nagpur
}

\begin{abstract}
The bio-inspired computation algorithms are the excellent tools for global optimization. These algorithms are very easy to understand and simple to implement. These algorithms especially dominate the classical optimization methods. Particle Swarm Optimization (PSO) is a global optimization algorithm that originally took its inspiration from the biological examples by swarming, flocking and herding phenomena in vertebrates. This paper presents facial emotion recognition system using PSO for different video clips with different cameras, at different distances and light intensity changes. The analysis is done for recognizing "Happy" emotion from other emotions. The comparison of facial emotion recognition system using other techniques and PSO is done. It is found that PSO has better results over other techniques in terms of accuracy and time required.
\end{abstract}

\section{Keywords}

Bio-inspired Computing, Particle Swarm Optimization, Lucas-Kanade algorithm

\section{INTRODUCTION}

Biologically Inspired Computing is a field of study that loosely knits together subfields related to the topics of connectionism, social behavior and emergence. It represents a class of algorithms focusing on efficient computing, e.g. for optimization processes and pattern recognition. Bio-inspired systems rely on system architectures for massively distributed and collaborative systems, e.g. for distributed sensing and exploration. Bio-inspired networking is a class of strategies for efficient and scalable networking under uncertain conditions, e.g. for delay tolerant networking. It is often closely related to the field of swarm intelligence (SI), artificial immune system (AIS) and cellular signaling pathways

In recent years, the Intelligent Human-Computer Interaction (HCI) technologies have attracted more and more attention. In previous research, $55 \%$ of face-to-face human communication is transferred by facial expressions. It shows that the facial expressions play an important role in social interactions with other human beings. For this reason, facial expression is also an important part in HCI. Thus, automatic Facial Expression Recognition in human-computer environment is essential and challenging.

Authors have developed an algorithm using particle swarm optimization (PSO) that is successfully applied, initially to detect "Happy" emotion. PSO is found to be very efficient and effective in solving a variety of problems that involve optimization also. PSO in its original form or with modifications is applied in solving different types of problems, such as electrical power systems [1], neural networks training [2], clustering problems [3] and task assignment problems [4], etc. However, concept of applying PSO to emotion detection is new and the developments in this field are going on. We implemented the algorithm into a computer system and tested it with various video clips. In this system, an action unit is specified at run time on the face of the subject and Lucas-Kanade algorithm helps us to automatically track its respective position in real time as subject expresses different emotions. This real time positions are processed instantly using particle swarm optimization to identify and display the emotion as "Happy" or "Not Happy" for each frame in video stream. The results obtained are very promising both in terms of accuracy and speed of detection.

\section{FACIAL EMOTION RECOGNITION}

Facial expressions are the facial changes in response to a person's internal emotional states, intentions, or social communications. Facial expression analysis has been an active research topic. Suwa et al. [5] presented an early attempt to automatically analyze facial expressions by tracking the motion of 20 identified spots on an image sequence in 1978. Y. Yacoob [6] tried to build computer systems to help us understand \& use the natural form of human communication in 1995. Prior research on emotion recognition from speech has been done to develop systems using acoustic features such as pitch, energy, and durations of the speech [7, 8]. Such efforts have focused on a few basic emotion classes such as anger, sadness, happiness, and other "universal" emotions. Lee [10] applied Fuzzy Inference (FIS) to emotion recognition. FIS based on fuzzy rules has been applied to numerous engineering applications such as control, signal processing, and pattern classification problems.

An intelligent system for facial emotion recognition was developed by many researchers using Fuzzy Logic [11], Neural Network [12, 13] and Neurofuzzy Logic [14]. Support vector machine (SVM), which were introduced from statistical learning theory by Vapnik (1995), have received considerable attention \& have been extensively used in features classification. Least squares support vector machine (LS-SVM) [15] proposed by Suykens and Vandewalle (1999) is used for facial emotion detection. Compared with the traditional neural network method, this method has advantages such as fast learning speed, global optimum, and strong generalization ability, and its results are apparently better than those of pattern recognitions. However, there is a prominent problem in the specific application of LS-SVM, which is how to select the key parameters of it, such as the balance parameter $C$ and kernel function parameter. Generalization performance of LS-SVM depends on a good 
setting of its parameters. However, traditional parameters selection is carried out by iterative experiments and the method needs the experience of users and the precision is influenced by users. Moreover, the method takes a long time. A recent algorithm that has been found to be very efficient and effective in solving a variety of problems that involve optimization or searching is the Particle Swarm Optimization (PSO) algorithm. PSO is used for facial Human Face Recognition by Bashir Ghandi et al[17,18]. A novel approach is presented to facial emotion detection using a modified Particle Swarm Optimization algorithm, which is called Guided Particle Swarm Optimization (GPSO). The approach involves tracking the movements of 10 Action Units (AUs) placed at appropriate points on the face of a subject and captured in video clips.

PSO is a parallel population-based computation technique which is proposed by Kennedy and Eberhart in 1995[16]. The main advantages of the PSO algorithm can be summarized as: simple concept, easy implementation, robustness to control parameters, and computational efficiency when compared with other mathematical algorithms and other heuristic optimization techniques. PSO can generate high-quality solutions within shorter computation time and have more stable convergence characteristic than other stochastic methods. So design of a novel approach to Facial Emotion Detection using Particle Swarm Optimization algorithm was the main focus of the work carried out.

\section{DEVELOPMENT OF FACIAL EMOTION RECOGNITION SYSTEM USING PSO}

Flowchart of the major functions of the facial emotion recognition system is shown in Figure 2. First video is converted to sequential image frames. The frames are converted at the rate of 25 frames per second. Total 50 frames are considered for analysis. This image frame is firstly preprocessed to reduce noise and also prepare image for further processing. Image Processing is basically converting colored image into equivalent grayscale image. This is done, so that the intensity value of each pixel can be extracted. After converting video into frame and smoothing up of images, apply action unit on the first frame of video. The first frame of each video is assumed to be Neutral image. The changes in movements of lips are considered for detection of facial emotion because the emotion can be very well expressed by changing the position of lips. $10 \times 10$ dimensional search space is created around the control point.

In current research work modification to the Particle Swarm Optimization (PSO) algorithm is used for the purpose applying to emotion detection. This algorithm [18], which is called Guided Particle Swarm Optimization (GPSO), involves studying the movements of specific point, called action unit (AU), placed on the face of a subject, as the subject expresses different emotions. A swarm of particles is defined such that each particle consists of components from the neighborhood of AU. However, instead of applying the pure PSO on the swarm to detect emotions, we used this algorithm to take into account the position of the AU - thus, the swarm is effectively guided to converge on the path of the AU. The approach is working very well and made the swarm to converge very quickly to identify the emotion being expressed.

PSO is a population-based search algorithm designed initially to simulate the social behavior of birds in a flock as they fly in search of food. A PSO algorithm maintains a swarm of particles, where each particle represents a potential solution. Also each particle maintains:

- Position in search space (solution \& fitness)

- Velocity

- Individual best position

In addition, the swarm maintains its global best position.

PSO is initialized with a group of random particles (solutions) and then searches for optima by updating generations. In every iteration, each particle is updated by following two "best" values. The first one is the best solution (fitness) it has achieved so far. (The fitness value is also stored.) This value is called pbest. Another "best" value that is tracked by the particle swarm optimizer is the best value, obtained so far by any particle in the population. This best value is a global best and called gbest. When a particle takes part of the population as its topological neighbors, the best value is a local best and is called lbest.

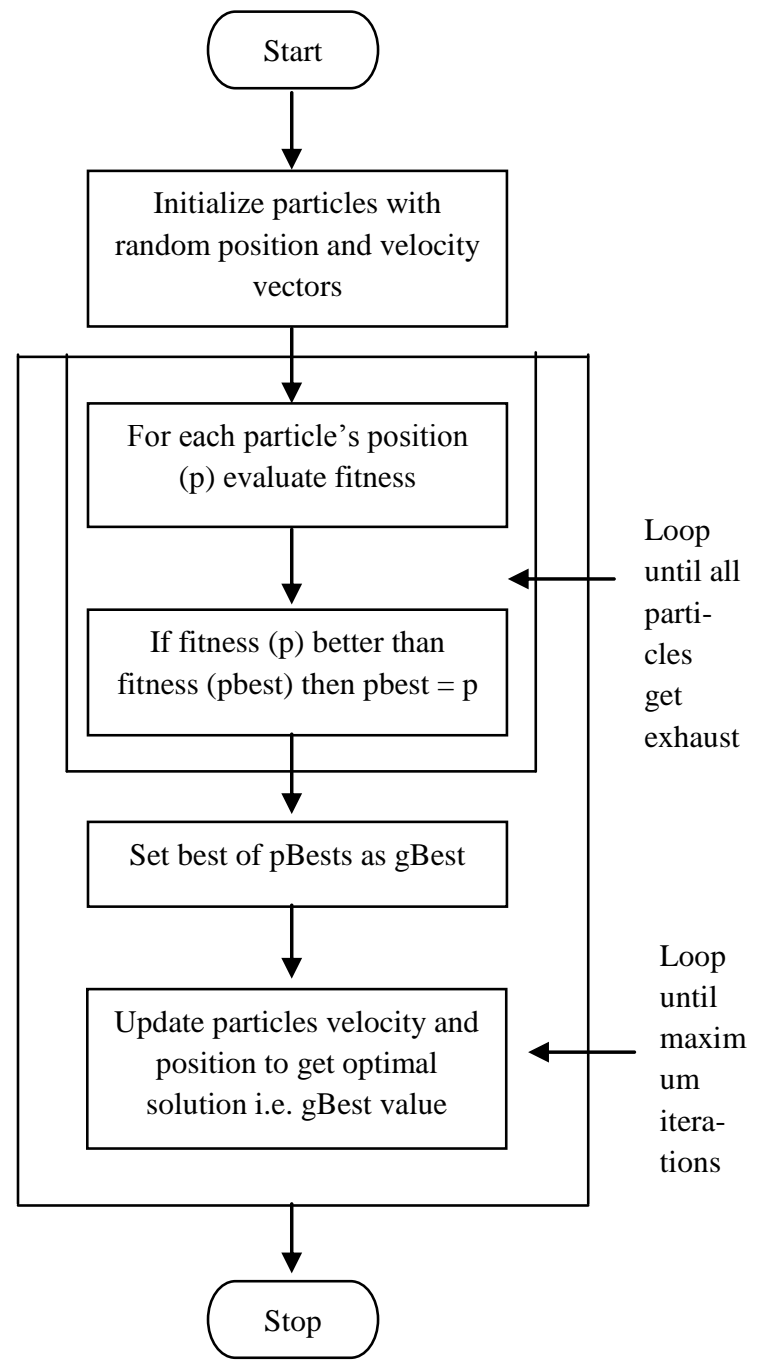

Figure 1: Flow chart for Particle Swarm Optimization Algorithm

Figure 1 shows flow chart for Particle Swarm Optimization Algorithm developed for facial emotion recognition system. After finding the two best values, the particle updates its velocity and positions with following equation (a) and (b). 
$\mathrm{v}[]=\mathrm{v}[]+\mathrm{c} 1 * \operatorname{rand}() *($ pbest []$-\operatorname{present}[])+\mathrm{c} 2 * \operatorname{rand}() *$ (gbest[] - present[]) --- (a)

present []$=$ persent []$+\mathrm{v}[]---(b)$

$\mathrm{v}[]$ is the particle velocity, persent[] is the current particle (solution). pbest[] and gbest[] are defined as stated before. rand () is a random number between $(0,1) . \mathrm{c} 1, \mathrm{c} 2$ are learning factors.

In each iteration of the PSO algorithm, each swarm will update the positions of its particles as usual and obtains its best position. These best positions are then compared. The swarm whose best position is closest to its target is considered to have found a solution. For example if that swarm happens to be the happy-targeting swarm, then the current state of the frame is identified as happy. We note that these computations are repeated for each frame in the video clip. Thus, the number of iterations for the algorithm is simply the number of frames in the video clip.

\section{LUCAS-KANADE OPTICAL FLOW ALGORITHM}

The facial emotion recognition system is developed using particle swarm optimization and lucas-kanade algorithm and is implemented using MATLAB. The Lucas-Kanade optical flow algorithm [19] is used to place the control point or Action Unit (AU) at run time on the first frame of the video sequence consisting of 50 frames in it. In computer vision, the Lucas-Kanade method is a widely used differential method for optical flow estimation. It assumes that the flow is essentially constant in a local neighbourhood of the pixel under consideration, and solves the basic optical flow equations for all the pixels in that neighbourhood, by the least squares criterion. By combining information from several nearby pixels, the Lucas-Kanade method can often resolve the inherent ambiguity of the optical flow equation. It is also less sensitive to image noise than point-wise methods. On the other hand, since it is a purely local method, it cannot provide flow information in the interior of uniform regions of the image. The Lucas-Kanade method assumes that the displacement of the image contents between two nearby instants (frames) is small and approximately constant within a neighborhood of the point $p$ under consideration. Lucas Kanade algorithm helps to track the action unit placed on first frame in real time as the subject expresses different emotions. This real time position is processed instantly based on particle swarm optimization technique to identify and display the "Happy" or "Not Happy" emotion.

\section{EXPERIMENTAL RESULTS}

The particle swarm optimization discussed in section III is implemented using MATLAB. The Lucas-Kanade optical flow algorithm is used to mention the control point or Action Unit (AU) at run time on the face of the first frame in the subject consisting of 50 frames in it. Lucas Kanade algorithm helps to track 'Happy' emotion in real time as the subject expresses different emotions. This real time position is processed instantly based on particle swarm optimization technique to identify and display the 'Happy' emotion. Flowchart of the major functions of the facial emotion recognition system is shown in Figure 2. First video is converted to sequential image frames. This image frame is firstly pre-processed to reduce noise and also prepare image for further processing. Image Processing is basically converting colored image into equivalent grayscale image. This is done, so that the intensity value of each pixel can be extracted. Then apply action unit on appropriate portion of face. Here we used mouth because the emotion can be very well expressed by changing the position of lips. Apply Particle Swarm Optimization to get optimized value to detect facial emotion of face into "Happy" or "Not Happy" as basic output of system. The software can be extended to find the results of more than 50 frames in the single subject. Figure 3 shows placement of real time AU on the first frame of subject. Two dimensional rectangular domains is defined around the AU and Particles are then defined to have a component in the domain, effectively creating a 10-dimensional search space within which particles fly in search of a solution. Figure 4 shows how search space with the particles with same intensity inside it. Figure 5 shows the result of particle swarm optimization indicating 'Happy' emotion distinctly and all other emotions as 'Not Happy' emotion.

Table 1 shows the detailed analysis of 5 video sequences, each of 50 frames with front faces. It can be seen that facial emotion detection using particle swarm optimization gives very promising success rate after applying the Lucas-Kanade algorithm if the action unit selection is proper for the designed system. The slight degradation in success rates occurs in $3^{\text {rd }}$ video because of the fact that motions are not small from frame to frame which attributed to the fact that the action unit that are placed at run time on lips may move slighty away from their original placement position over the time. However, we still consider these success rates to be very good. This slight degradation in accuracy is very insignificant if we consider advantage of real time nature of the system.

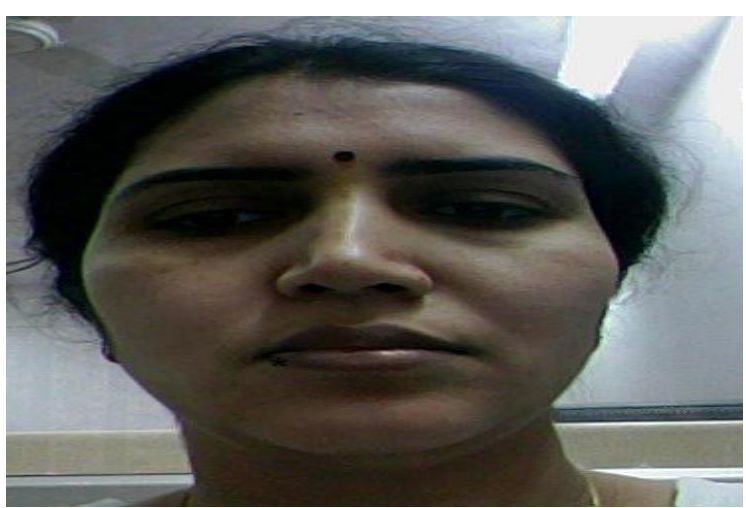

Figure 3: The Action Unit is specified in real time

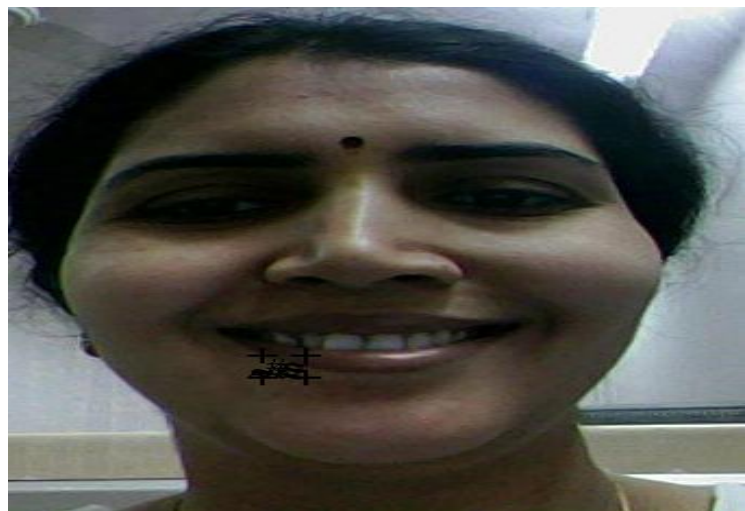

Figure 4: Search Space with particles of same intensity inside it 


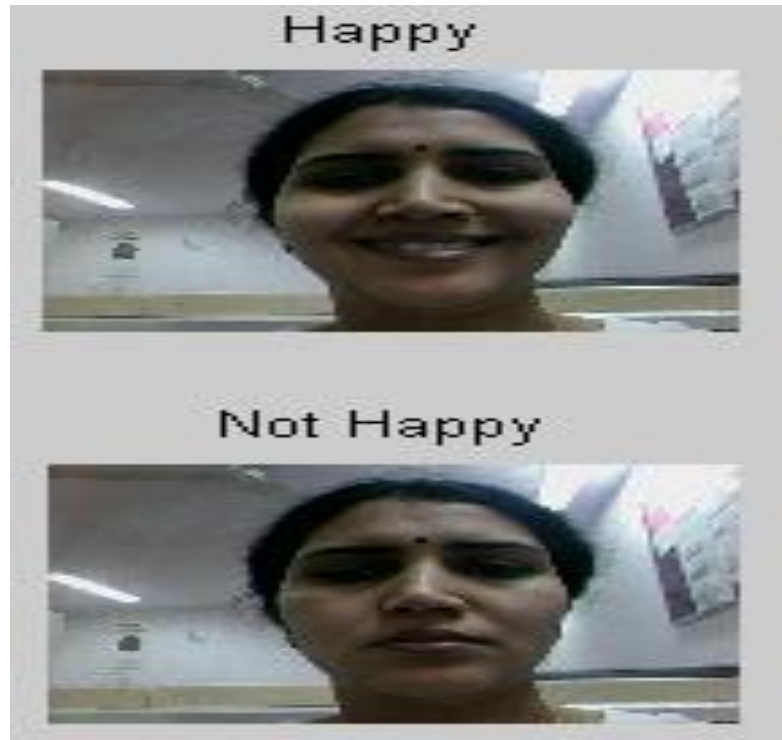

Figure 5: The Happy emotion identified by the system for front side face

Figure 6 shows original image for side face analysis. Figure 7 shows placement of real time action unit on the first frame of subject. Two dimensional rectangular domains is defined around the action and particles are then defined to have a component in the domain, effectively creating a 10dimensional search space within which particles fly in search of a solution. Figure 8 shows search space with the particles with same intensity point inside it. Figure 9 shows the result of facial emotion detection system using particle swarm optimization indicating "Happy" and "Not Happy" emotion for side face.

The detailed analysis of 4 different video clips, each of 50 frames with side faces is given in Table 2. The detailed analysis for facial emotion recognition (FER) system using particle swarm optimization (PSO) for various cameras with different resolution and pixel size is given in Table 3 . Camera3 is an analog broadcasting camera with $725 \times 526$ resolution. The analysis of facial emotion for different brightness is given in Table 4. Analysis of video clip of single person at various distances is given in Table 5 and we find that the results obtain using designed system is $90 \%$ for the distance of 20 feet also. Each video clip each considered with 50 frames and we got very promising results with particle swarm optimization with average accuracy of 92 to $96 \%$. The time required for getting the result of "Happy" or "Not Happy" emotion is very less ie $25-30 \mathrm{msec}$.

A group of students is working to design and develop an intelligent system for facial emotion recognition system under the guidance of Prof. S. D. Giripunje. The comparative study of facial emotion recognition system using PSO and other techniques developed by a group is given in Table 6 . The technique developed for facial emotion recognition system using PSO proves to be better solution for the same in terms of accuracy and time required to get the result.

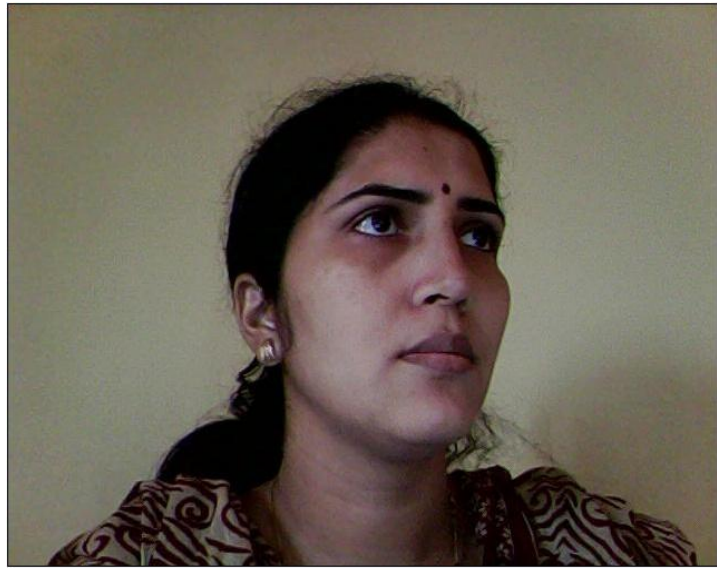

Figure 6: Original image for side face analysis

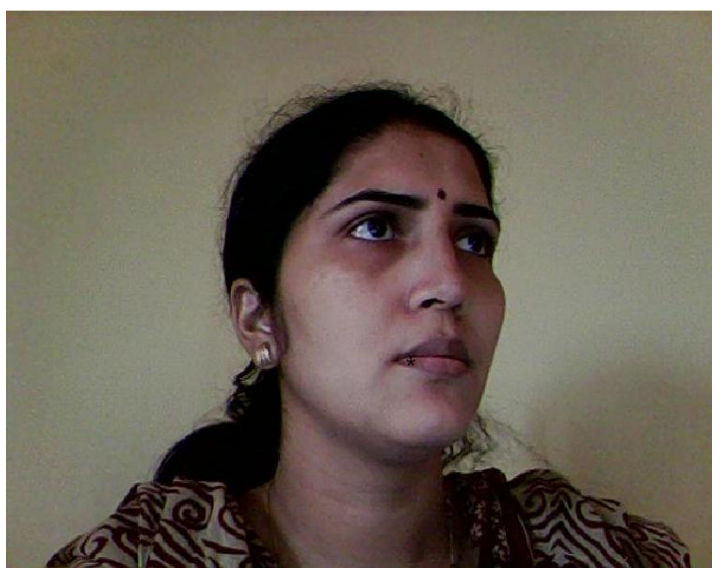

Figure 7: Action unit on the first frame of subject

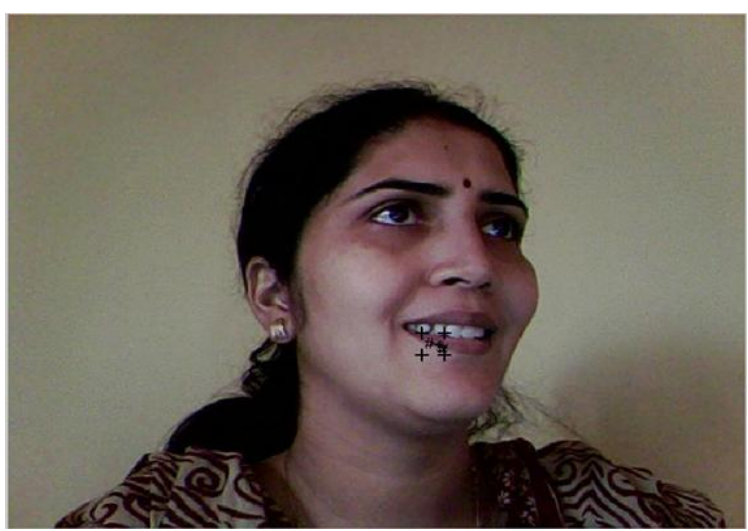

Figure 8: Search space 


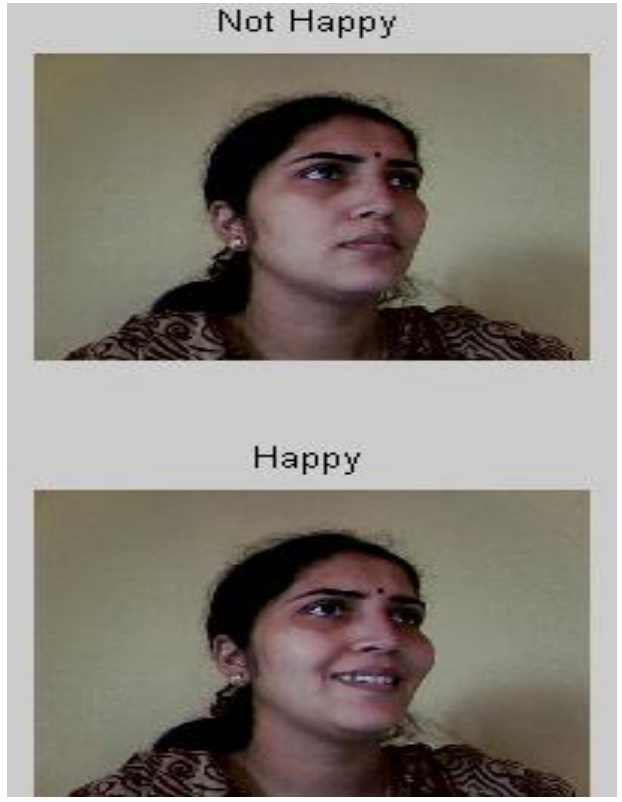

Figure 9: Result of facial emotion detection system using particle swarm optimization indicating "Happy" and "Not Happy" emotion for side face.

In terms of future research work in this project, authors intend to increase the number of AUs and find out the success rate for the same. The Multiswarm PSO will be the next step to detect the six basic human emotions viz. angry, disgust, fear, happy, sad, and surprise with improved results.

\section{CONCLUSIONS}

In this paper, authors have presented the results obtained by PSO with lucas-kanade (LK) optical flow method, which is successfully applied, initially to detect "Happy" emotion. The AU is specified at real time and the LK algorithm helps to keep track of position of AU. The system can be improved to detect the six basic emotions. This system can be then used in any computer systems, Forensic Applications by Police, Psychiatric Applications and can be easily deployable into robot for real time applications without compromising the efficiency of the system

\section{REFERENCES}

[1] V. Miranda and N. Fonseca, "EPSO -- Evolutionary Particle Swarm Optimization, a New Algorithm with Applications in Power Systems", Proceedings of the Asia Pacific IEEE/PES Transmission and Distribution Conference and Exhibition, 2002, vol. 2, pp. 745-750.

[2] M. Settles and B. Rylander. , "Neural Network Learning using Particle Swarm Optimizers", Advances in Information Science and Soft Computing, 2002, pp. 224226.

[3] M.G. Omran, A.P. Engelbrecht, and A. Salman, "Particle Swarm Optimization Method for Image Clustering", International Journal on Pattern Recognition and Artificial Intelligence, , 2005, vol. 19, no. 3, pp. 297-322.

[4] Salman, I. Ahmad, and S. Al-Madani, "Particle Swarm Optimization for Task Assignment Problem", Microprocessors and Microsystems, 2002, vol. 26, no. 8, pp. 363-371.
[5] M. Suwa, N. Sugie, and K. Fujimora. A preliminary note on pattern recognition of human emotional expression. In International Joint Conference on Pattern Recognition, pages 408-410, 1978.

[6] Y. Yacoob, H.-M. Lam, and L. Davis. Recognizing faces showing expressions. In Proc. Int.Workshop on Automatic Face- and Gesture-Recognition, pages 278283, Zurich, Switserland, 1995.

[7] C.M. Lee, S. Narayanan, and R. Pieraccini, "Recognition of negative emotions from the speech signal," in Proc. Automatic Speech Recognition and Understanding, Dec 2001.

[8] V. Petrushin, "Emotion in speech: Recognition and application to call centers," Artificial Neural Net. In Engr.(ANNIE '99), 1999.

[9] R. Plutchik, The Psychology and Biology of Emotion, HarperCollins College, New York, NY, 1994.

[10] 10.Chul Min Lee and Shrikanth Narayanan, "Emotion Recognition Using a Data-Driven Fuzzy Inference System" Eurospeech, 2003, Geneva

[11] Esau, N., Wetzel, E., Kleinjohann, L., Kleinjohann, B., "Real-Time Facial Expression Recognition Using a Fuzzy Emotion Model" Fuzzy Systems Conference, 2007. FUZZ-IEEE 2007, 23-26 July 2007, 1 - 6 .

[12] Amav Bhavsar and Hima M. Patel, "Facial Expression Recognition Using Neural Classifier and Fuzzy Mapping”, IEEE Indicon 2005 Conference, Chennai, India, 11-13 Dec. 2005.

[13] Adnan Khashman, “A Modified Backpropagation Learning Algorithm With Added Emotional Coefficients", IEEE Transactions On Neural Networks, VOL. 19, NO. 11, November 2008.

[14] Chatterjee, S.; Hao Shi, "A Novel Neuro Fuzzy Approach to Human Emotion Determination", International Conference on Digital Image Computing: Techniques and Applications (DICTA), 2010, 282 - 287.

[15] Shuaishi Liu, Yantao Tian, Cheng Peng, Jinsong Li, "Facial Expression Recognition Approach Based on Least Squares Support Vector Machine with Improved Particle Swarm Optimization Algorithm", Proceedings of the 2010 IEEE International Conference on Robotics and Biomimetics December 14-18, 2010, Tianjin, China.

[16] R. Eberthart, and J. Kennedy, "A new optimizer using particle swarm theory," in Proceeding of the 6th international symposium on micro machine and human science. 1995 , pp. 39-43.

[17] Bashir Mohammed Ghandi, R. Nagarajan and Hazry Desa, "Particle Swarm Optimization Algorithm for Facial Emotion Detection", IEEE Symposium on Industrial Electronics and Applications, October 4-6, 2009, Malaysia.

[18] Bashir Mohammed Ghandi, R. Nagarajan and Hazry Desa, "Facial Emotion Detection using GPSO and Lucas-Kanade Algorithms", International Conference on Computer and Communication Engineering (ICCCE 2010), 11-13 May 2010, Kuala Lumpur, Malaysia

[19] B. D. Lucas and T. Kanade, "An iterative image registration technique with an application to stereo vision," in Proceedings of Imaging Understanding Workshop, pp. 121-130, 1981. 
[20] Ketki Patil, Prof S D Giripunje, Dr Preeti Bajaj, "Facial expression recognition and Head Tracking in Video Using Gabor Filter", Third International Conference on Emerging Trends in Engineering and Technology, 2010.

[21] Mahima Agrawal, Prof S. D. Giripunje, "Recognitizing Facial Expression using PCA and Genetic Algorithm",

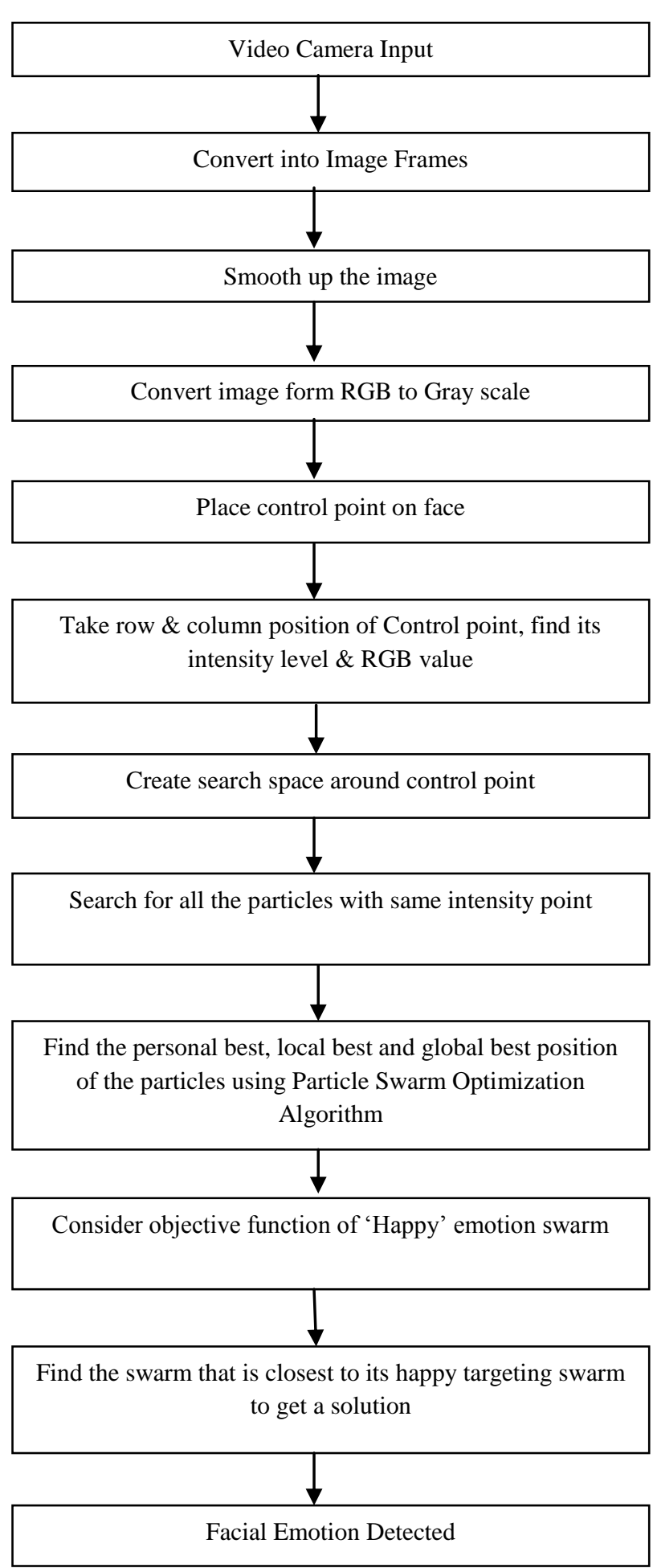

ICCSI-2011(International Conference on Computer Science and Informatics) organized by IIMT, Bhubaneswar.
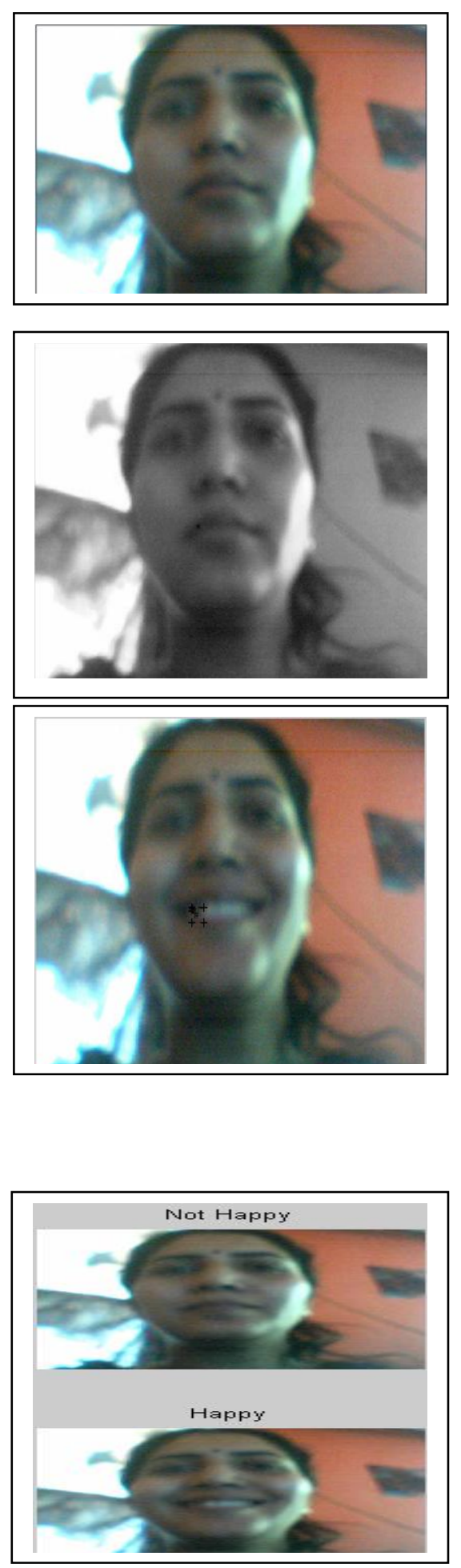

Figure 2: Flow chart for the Facial Emotion Recognition system using PSO 
Table 1. Analysis of result of "Happy" and "Not Happy" emotion by particle swarm optimization for front faces

\begin{tabular}{|c|c|c|c|c|c|c|}
\hline $\begin{array}{l}\text { Video } \\
\text { clips }\end{array}$ & Camera & Distance & Facial Emotion & $\begin{array}{c}\text { No. of } \\
\text { Frames }\end{array}$ & $\begin{array}{c}\text { Correct } \\
\text { Result }\end{array}$ & $\begin{array}{c}\% \\
\text { Accuracy }\end{array}$ \\
\hline \multirow[t]{2}{*}{1} & \multirow[t]{2}{*}{ Camera2 } & \multirow[t]{2}{*}{$50 \mathrm{~cm}$} & Happy & 25 & 25 & \multirow[t]{2}{*}{90} \\
\hline & & & Neutral / Not Happy & 25 & 20 & \\
\hline \multirow[t]{2}{*}{2} & \multirow[t]{2}{*}{ Camera1 } & \multirow[t]{2}{*}{1 feet } & Happy & 25 & 24 & \multirow[t]{2}{*}{96} \\
\hline & & & Neutral / Not Happy & 25 & 24 & \\
\hline \multirow[t]{2}{*}{3} & \multirow[t]{2}{*}{ Camera2 } & \multirow[t]{2}{*}{1 feet } & Happy & 20 & 19 & \multirow[t]{2}{*}{88} \\
\hline & & & Neutral / Not Happy & 30 & 25 & \\
\hline \multirow[t]{3}{*}{4} & \multirow[t]{3}{*}{ Camera2 } & \multirow[t]{3}{*}{2 feet } & Happy & 15 & 15 & \multirow[t]{3}{*}{90} \\
\hline & & & Towards Happy & 10 & 05 & \\
\hline & & & Neutral / Not Happy & 25 & 25 & \\
\hline \multirow[t]{2}{*}{5} & \multirow[t]{2}{*}{ Camera3 } & \multirow[t]{2}{*}{2 feet } & Happy & 18 & 17 & \multirow[t]{2}{*}{92} \\
\hline & & & Neutral / Not Happy & 32 & 29 & \\
\hline
\end{tabular}

Table 2: Analysis of result of "Happy" and "Not Happy" emotion by particle swarm optimization for side faces

\begin{tabular}{|c|c|c|c|c|c|c|c|}
\hline \multirow{2}{*}{$\begin{array}{l}\text { Video } \\
\text { Clips }\end{array}$} & \multirow{2}{*}{$\begin{array}{c}\text { Camera } \\
\text { Used }\end{array}$} & \multirow[t]{2}{*}{ Distance } & \multirow[t]{2}{*}{ Facial Emotion } & \multirow{2}{*}{$\begin{array}{c}\text { No. of } \\
\text { Frames }\end{array}$} & \multicolumn{2}{|c|}{ Result } & \multirow{2}{*}{$\begin{array}{c}\% \\
\text { Accuracy }\end{array}$} \\
\hline & & & & & Correct & Wrong & \\
\hline \multirow[t]{3}{*}{1} & \multirow[t]{3}{*}{ Camera 2} & \multirow[t]{3}{*}{$50 \mathrm{~cm}$} & Нарру & 20 & 20 & 00 & \multirow[t]{3}{*}{84} \\
\hline & & & Towards Happy & 10 & 09 & 01 & \\
\hline & & & Neutral / Not Happy & 20 & 13 & 07 & \\
\hline \multirow[t]{2}{*}{2} & \multirow[t]{2}{*}{ Camera 2} & \multirow[t]{2}{*}{2 feet } & Happy & 27 & 25 & 02 & \multirow[t]{2}{*}{96} \\
\hline & & & Neutral / Not Happy & 23 & 23 & 00 & \\
\hline \multirow[t]{2}{*}{3} & \multirow[t]{2}{*}{ Camera 3} & \multirow[t]{2}{*}{2 feet } & Happy & 25 & 25 & 00 & \multirow[t]{2}{*}{92} \\
\hline & & & Neutral / Not Happy & 15 & 11 & 04 & \\
\hline \multirow[t]{3}{*}{4} & \multirow[t]{3}{*}{ Camera 2} & \multirow[t]{3}{*}{1 feet } & Happy & 15 & 15 & 00 & \multirow[t]{3}{*}{84} \\
\hline & & & Towards Happy & 10 & 10 & 00 & \\
\hline & & & Not Happy & 25 & 17 & 08 & \\
\hline
\end{tabular}

Table 3: Result of FER system using PSO with different cameras

\begin{tabular}{|c|c|c|c|c|c|}
\hline \multirow{2}{*}{$\begin{array}{c}\text { Video Clips } \\
\text { with } \\
\text { different } \\
\text { cameras }\end{array}$} & \multirow[t]{2}{*}{ Facial Emotion } & \multirow{2}{*}{$\begin{array}{c}\text { No. of } \\
\text { Frames }\end{array}$} & \multicolumn{2}{|c|}{ Result } & \multirow{2}{*}{$\begin{array}{c}\% \\
\text { Accuracy }\end{array}$} \\
\hline & & & Correct & Wrong & \\
\hline \multirow[t]{2}{*}{1} & Happy & 25 & 25 & 00 & \multirow[t]{2}{*}{90} \\
\hline & Neutral / Not Happy & 25 & 20 & 05 & \\
\hline \multirow[t]{2}{*}{2} & Happy & 25 & 25 & 00 & \multirow[t]{2}{*}{98} \\
\hline & Neutral / Not Happy & 25 & 24 & 01 & \\
\hline \multirow[t]{2}{*}{3} & Happy & 18 & 17 & 01 & \multirow[t]{2}{*}{92} \\
\hline & Neutral / Not Happy & 32 & 29 & 03 & \\
\hline
\end{tabular}


Table 4: Result of FER system using PSO for different brightness of light on face

\begin{tabular}{|c|c|c|c|c|c|}
\hline \multirow{2}{*}{$\begin{array}{c}\text { Video Clips } \\
\text { with } \\
\text { different } \\
\text { brightness } \\
\end{array}$} & \multirow[t]{2}{*}{ Facial Emot-ion } & \multirow{2}{*}{$\begin{array}{l}\text { No. of } \\
\text { Frames }\end{array}$} & \multicolumn{2}{|c|}{ Result } & \multirow{2}{*}{$\begin{array}{c}\% \\
\text { Accuracy }\end{array}$} \\
\hline & & & Correct & Wrong & \\
\hline \multirow{2}{*}{$\begin{array}{c}1 \\
\text { Brightness is } \\
\text { less }\end{array}$} & Happy & 25 & 25 & 00 & \multirow[t]{2}{*}{90} \\
\hline & Neutral / Not Happy & 25 & 20 & 05 & \\
\hline \multirow{2}{*}{$\begin{array}{c}2 \\
\text { Brightness is } \\
\text { more }\end{array}$} & Happy & 25 & 25 & 00 & \multirow[t]{2}{*}{98} \\
\hline & Neutral / Not Happy & 25 & 24 & 01 & \\
\hline \multirow{2}{*}{$\begin{array}{c}3 \\
\text { Light on one } \\
\text { side of face }\end{array}$} & Happy & 25 & 25 & 00 & \multirow[t]{2}{*}{92} \\
\hline & Neutral / Not Happy & 15 & 11 & 04 & \\
\hline
\end{tabular}

Table 5: Result of FER system using PSO at different distances

\begin{tabular}{|c|c|c|c|c|c|}
\hline \multirow{2}{*}{$\begin{array}{l}\text { Video Clips } \\
\text { at different } \\
\text { distances }\end{array}$} & \multirow[t]{2}{*}{ Facial Emo-tion } & \multirow{2}{*}{$\begin{array}{c}\text { No. of } \\
\text { Frames }\end{array}$} & \multicolumn{2}{|c|}{ Result } & \multirow{2}{*}{$\begin{array}{c}\% \\
\text { Accuracy }\end{array}$} \\
\hline & & & Correct & Wrong & \\
\hline \multirow{2}{*}{$\begin{array}{c}1 \\
(50 \mathrm{~cm})\end{array}$} & Happy & 25 & 25 & 00 & \multirow[t]{2}{*}{100} \\
\hline & Neutral / Not Happy & 25 & 25 & 00 & \\
\hline \multirow{2}{*}{$\begin{array}{c}2 \\
(1 \mathrm{feet})\end{array}$} & Happy & 25 & 25 & 00 & \multirow[t]{2}{*}{98} \\
\hline & Neutral / Not Happy & 25 & 24 & 01 & \\
\hline \multirow{2}{*}{$\begin{array}{c}3 \\
(2 \text { feet })\end{array}$} & Happy & 25 & 25 & 00 & \multirow[t]{2}{*}{100} \\
\hline & Neutral / Not Happy & 25 & 25 & 00 & \\
\hline
\end{tabular}

Table 6: Comparative study of FER system using different techniques

\begin{tabular}{|c|l|c|c|}
\hline Sr. No. & \multicolumn{1}{|c|}{ Technique Used } & \% Efficiency & Time Required \\
\hline 1. & $\begin{array}{l}\text { Gabor Filter and Neural Network } \\
{[20]}\end{array}$ & 89 & $40 \mathrm{sec}$ \\
\hline 2. & $\begin{array}{l}\text { Principle Component Analysis and } \\
\text { Genetic Algorithm [21] }\end{array}$ & 91.18 & $36 \mathrm{sec}$ \\
\hline 3. & Particle Swarm Optimization & Avg 92 to $96 \%$ & 25 to $30 \mathrm{sec}$ \\
\hline
\end{tabular}

